\title{
Using Course Syllabi to Uncover Opportunities for Curriculum- Integrated Instruction
}

A syllabus study was conducted to indicate potential directions for the library instruction program at the University of Notre Dame, a comprehensive Level One institution in Indiana. In addition to identifying those courses which might benefit from library instruction that are not currently utilizing these services, the authors also tested several hypotheses regarding library use. A total of 144 syllabi were collected from a random sample of classes and were analyzed to determine the degree to which library resources are utilized. A summary analysis of the course syllabi showed that 62 syllabi (43 percent) required no library use, and 82 syllabi (57 percent) required at least some library use. Further analysis of the data revealed that class size, discipline, and even days on which classes are taught have an impact on the extent to which any type of library component is included in syllabi. The disciplines with the highest percentage of required library research were arts/architecture and the social sciences, the disciplines with the lowest percentage of library use were business and the sciences/engineering. This study reinforces the value of examining course syllabi as a method for uncovering opportunities for instruction and outreach.
$\mathbf{T}$

oday's college students are challenged by an ever expanding world of information and research resources. Academic libraries have responded to this challenge by providing instruction in information literacy, defined by the American Library Association as a set of abilities requiring individuals to "recognize when information is needed and have the ability to locate, evaluate, and use effectively the needed information."

University libraries are teaching information literacy skills using a variety of instructional approaches, depending on the particular needs of the institution. These can include stand-alone credit courses, online information literacy instruction, and course-related or course-integrated instruction sessions. Many employ a tiered approach to instruction where certain skills are taught at an early level while other skills are taught later in the student's academic career. Implementation of a particular approach or program depends on many institutional and situational factors such as audience, purpose, budget, staffing, facilities, and time. ${ }^{2}$
Cheri Smith, Linda

Doversberger, Sherri Jones, Parker Ladwig, Jennifer Parker, and Barbara Pietraszewski

Cheri Smith is Coordinator of Instructional Services, Linda

Doversberger is Reference Specialist, Sherri Jones is Head, Information, Research and Instructional Services,

Parker Ladwig is Mathematics and Life Science Librarian, Jennifer

Parker is Architecture Librarian, and

Barbara Pietraszewski is Business Librarian, University of Notre Dame, Notre Dame, Indiana. Submitted for review June 8, 2011; accepted for publication August 19, 2011.

Reference \& User Services Quarterly, vol. 51, no. 3, pp. 263-71 (c) 2012 American Library Association. All rights reserved.

Permission granted to reproduce for nonprofit, educational use. 


\section{FEATURE}

Many librarians argue that course-integrated or curriculumintegrated instruction is a more effective model. Holliday and Fagerheim (2006) state that the goal of curriculum integrated instruction is "to sequence information literacy throughout the general education and upper division curriculum in ways that better meet students' needs as they advance in their coursework." ${ }^{\prime 3}$ According to Jacobson and Mark (2001), information literacy instruction is most effective when offered within the context of a specific class or specific assignment. ${ }^{4}$ Similarly, Bergen and MacAdam (1985) found that "students prosper most from any form of library instruction when it comes at a time of greatest need and relevance to their academic work." Grafstein (2002) advocates for teaching information literacy skills in the context of discipline-specific research paradigms, arguing that teaching generic information seeking skills focuses too much on information retrieval processes, ignoring a vital connection between equipping students with both knowledge about the subject-specific content and research practices of particular disciplines. ${ }^{6}$

A key to effective course integrated instruction is identifying appropriate courses where academic librarians can collaborate with faculty to teach information literacy. While formal in-class library instruction is ideal, there are other less formal ways to work with faculty to embed library resources into courses to improve the information literacy skills. These include the creation of pathfinders, bibliographies, webliographies, guides to the literature, and course guides. These tools can also be integrated into the university's courseware to provide more customized library research assistance, serving as a way of getting a toe in the door of classes for which there was not previously any library instruction. ${ }^{7}$

According to Williams, Cody, and Parnell (2004), the "key to embedding the library into the student experience is to be an integral part of the course work. The most detailed evidence of what that coursework entails is the syllabus. Therefore, obtaining and analyzing syllabi for existing and potential library collaboration are valuable endeavors for librarians." " Sayles (1985) also advocates the study of course syllabi, describing the syllabus as a "gold mine of information from which material can be extracted for a study guide and other applications. A thorough analysis of a syllabus enables librarians to respond with specific information services and allows them to complement the teaching function rather than play the traditional supplemental role." Recognizing the potential that course syllabi could play in revealing opportunities for further embedding the library services and resources into courses, either through course integrated instruction, the creation of course guides, or integration into the course management system, the authors determined to conduct a syllabus study.

\section{BACKGROUND INFORMATION}

The University of Notre Dame is a comprehensive Level 1 institution with an enrollment of approximately 8,400 undergraduates and 1,700 graduate students. An additional 1,700 students are enrolled in professional programs. Undergraduate degrees are offered in 62 programs within four colleges (Arts and Letters, Science, Engineering, and Business) and the School of Architecture. The First Year of Studies serves as the college for all incoming students, regardless of their intended program, providing full-time professional advisors to support the students as they complete the First Year curriculum and move successfully to a university program or major.

Notre Dame is supported by the Hesburgh Libraries, which comprises the main library and seven branches, has approximately 3.4 million volumes and 83,000 serial subscriptions, and employs 70 professional staff and 150 support staff. The Hesburgh Libraries have developed an information literacy plan based on a "tiered approach" to provide three progressively in-depth levels of library instruction. The first tier is aimed at creating a foundation of information literacy attainment. The second tier is advanced instruction integrated into classes taught in conjunction with upper level course work. The third tier involves credit based library research skills classes. Librarians at Notre Dame teach a credit class that is required of all chemistry majors and another general research strategies class offered as an elective.

Metrics are obtained on the first tier by the number of freshmen instructed through the required course, First Year of Composition (FYC). The First Year of Studies Librarian and the First Year of Studies Program have developed a set of learning outcomes for first year students and information literacy skills instruction has been an official component of the curriculum for FYC classes since 2001. Nearly all FYC classes receive formal library instruction (approximately 90-100 courses a year). However, each year roughly half of all University of Notre Dame students are able to test out of FYC classes based on SAT or International Baccalaureate scores, and the libraries have struggled to find ways to teach information literacy skills to these students.

At the second tier, metrics are obtained by the number of classes taught at the 200-400 level. During a typical year, the Libraries report around 260 course-integrated library instruction sessions for these class levels. This number is "selfreported" by the librarians to the Coordinator of Instructional Services. It has been our own observation that these course integrated sessions, presented within the context of a specific class and in relation to a specific assignment, have proven to be very successful. For this reason, these classes have become the focus of our study with the intent of uncovering more opportunities for course integrated instruction.

In addition to our formal instruction program, the Libraries have introduced new auxiliary services over the years to assist students with library research assignments, including the creation of course pages that direct students to resources and services that are selected to support research in specific classes and working with faculty to incorporate library resources into the university's course management system (CMS). In 2002, in conjunction with the introduction of a new CMS, a library committee was established to increase the library presence in classes. Committee members participated 
in training sessions for the new CMS, demonstrating how to add links to library resources and e-reserves. This effort resulted in greater numbers of faculty using e-reserves, but has had limited success for more "embedded" library services such as the integration of contact information for library subject specialists and inclusion of research databases and tools.

\section{LITERATURE REVIEW}

The idea of librarians analyzing course syllabi to gain information is certainly not new, but recent studies are relatively scarce. The earliest report found was a study conducted by Rambler at The Pennsylvania State University Libraries (Penn State) in $1979 .{ }^{10}$ The purpose of the study was to determine the instructional modes in effect among the various courses taught at Penn State in an attempt to increase library curriculum integration. Rambler defines a responsive library as a curriculum-integrated library. The author conducted a syllabus study to determine which subject areas, course levels, and specific courses make planned use of library resources, with the idea of using the findings to facilitate the creation of a responsive and curriculum-integrated library. A random sample of 162 courses was drawn from the schedule of classes for one term and syllabi collected from class instructors. A scaling category of "much," "some," and "none" to define library use via various instructional modes was used to analyze each syllabus. The results showed that 63 percent of the selected courses required no library use, with only 8 percent of the classes requiring much use of the library, causing the author to conclude that library resources are underused. Rambler advocated for the creation of faculty development programs which "include introduction to library resources and academic support services in order to increase use of instructional modes utilizing library resources." ${ }^{11}$

Lauer, Merz, and Craig (1989) followed the model established by Rambler and studied how much and what kind of library use college professors require at two private academic institutions, one with a liberal arts orientation (Houghton College) and one supporting both liberal arts and professional education (Aurora University). ${ }^{12}$ In this study, prescribed library use was defined as use of the library required by professors for successful completion of coursework, as indicated in course syllabi. The authors employed five levels of prescribed library use for the analysis of syllabi, rating each syllabus on a scale of 0-4, in ascending order of sophistication and weight. Syllabi were collected for courses offered in the 1988 semester at both schools. The study analyzed the data obtained from the syllabi for the amount of library use at each institution and the sophistication of library use required by different departments at each course level. Results showed that prescribed library use was relatively low at both institutions and that higher course levels generally required greater and more sophisticated use of the library. The authors concluded that, at least for these two institutions, "curricular emphasis is a poor predictor of relative library use, although the more professionally oriented curricula evidenced slightly higher levels of required use. Disciplines representing institutional strengths tend to place greater demands on the library than those de-emphasized by the college or university." ${ }^{13}$

Similarly, Bean and Klekowski (1993) described their analysis of 77 percent of the syllabi distributed in classes at DePaul University's Suburban Campus Libraries over a period of two years as a study of "categories of library use" in an effort to anticipate course library needs and work with appropriate faculty to incorporate library instruction into courses. ${ }^{14}$ One of the study's main objectives was to identify courses within the curriculum in which exposure to library services and resources would be useful and to work with the appropriate faculty member to incorporate library use into his/her course. The authors agreed that this "objective was only sparingly achieved." While they acknowledge that a few faculty members did begin to schedule regular library instruction classes after the syllabus study, most faculty were reluctant to change the structure of their courses to incorporate library use because of the time involved. ${ }^{15}$ On the other hand, the course syllabi analysis did allow librarians to have enough information and time to respond to library use needs, which was another objective of the study.

Dewald (2003) undertook a study to learn how much library use or research was expected of students by business faculty at Penn State. ${ }^{16}$ From the study of business syllabi, the author was able to develop strategies for outreach and improving service to the students and faculty in the business administration program. The author used a modified version of the categories used by Lauer, Merz, and Craig (1989), changing the categories to read "research or library use" instead of simply "library use." ${ }^{17}$ For this study, syllabi were examined for courses required of students for the completion of the Bachelor of Science in Business Administration degree at Penn State, Berks Campus, during the 2000-2001 and 2001-2002 academic years. This study proved to be quite helpful for getting to know both the curriculum and faculty expectations of student research in a discipline, as well as acquiring a view of what an individual student's research experience may be.

Williams, Cody, and Parnell (2004) were the first to analyze online syllabi for library use. ${ }^{18}$ The authors modified the original categories used by Lauer (1989) and created two more categories of their own. They collected and evaluated 828 available online syllabi from over 3,000 class sections taught at the University of North Carolina Wilmington during two semesters. Reviewing the uses and potential uses of the library through the perspective of the syllabus revealed many opportunities for the library to pursue in the areas of collection development, instruction, and resource awareness. Their examination of syllabi produced a wealth of ideas for collaborating with faculty, including involving the faculty with the design of assignments, in what they hoped would be a "deeper involvement with a broader audience of faculty." ${ }^{19}$ One of the main objectives for conducting the study was to identify courses that would benefit from instruction that were not currently utilizing the service. As a result of the study, the 


\section{FEATURE}

library has begun a third instruction option. In addition to the one shot classes and drop in clinics, they are now offering a ten minute introduction to library services. ${ }^{20}$

Most recently, VanScoy and Oakleaf (2008) employed a syllabus method to investigate the research skills required of students during their first semester of study to provide evidence for curriculum-integrated instruction. ${ }^{21} \mathrm{~A}$ random sample of students was selected and their course syllabi analyzed to determine which skills to include in the most basic curriculum-integrated instruction tier. The categories used in this study focused on outcomes students are required to demonstrate through the completion of tasks rather than the amount of library use or the assignment outputs. The findings revealed that 97 percent of first year students are required to find research resources in their first semester of college and suggests that previous recommendations regarding tiered instructional approaches should be reexamined.

\section{METHOD}

Recognizing the value of examining course syllabi to uncover opportunities to offer library instructional services at Notre Dame and to further embed our services and resources into the curriculum, a group of librarians involved with instruction decided to conduct their own syllabus study. In addition to our main objective of identifying those courses which might benefit from library instruction that are not currently utilizing these services, we also wanted to test several hypotheses. Based on our own observations over the years, we predicted that:

1. The majority of syllabi would require no library use.

2. The level of the class (freshman-100, sophomore-200, etc.) would affect the amount and degree of library research required.

3. The subject discipline of the class (humanities, social sciences, etc.) would affect the amount and degree of library research required. Further, science-technology syllabi would require less library research than other subjects.

4. The use of the University's CMS would be low.

5. For those classes requiring some or much library use, formal library instruction services would be underutilized.

We gathered from the registrar a list of 5,173 course sections offered by the university during the Spring Semester 2009. We used the following process to obtain a sample of classes taught across the university.

First, we eliminated several types of classes:

- 36 First Year Composition classes were eliminated because they were already known to have a library component integrated into their syllabi.

- 2,433 graduate level classes were eliminated since the focus of our study was on library research required in undergraduate classes.
- 89 laboratory classes were eliminated because we believed that any library research skills were more likely to be listed as part of the syllabi for classes taken in conjunction with the lab.

- 1,119 directed research classes were also eliminated.

We were left with 1,496 unique class numbers to sample. The team then used a simple random sampling process to come up with a sample of 300 classes from the 1,496 unique class numbers. For those classes with multiple sections, the original list was randomly sorted so sections numbers would not be in order. The first section number from the randomly sorted list was chosen. For those classes having two of the same section number, the one with the most days of class was chosen. This only affected 8 classes.

After the classes were selected, each of the six team members selected 50 classes to contact to ask for a copy of the course syllabus. Team members e-mailed the instructor of record asking for a copy of the syllabus for his/her class (see the appendix for the standardized e-mail.) and then, if necessary, sent up to two follow-up e-mails. A few instructors responded that they had already been contacted by one of the team members, and we became aware that some of the selected classes were cross-listed. Consequently 25 cross-listed classes were removed from our sample, leaving us with a total of 275 possible classes.

In all, 144 syllabi were received, resulting in a return rate of 52 percent. Table 1 shows the distribution of syllabi received across the various disciplines.

After gathering the syllabi, the team rated each syllabus to identify the degree of sophistication of library usage, using the scale originally proposed by Lauer, et al. (1989), and slightly revised by Dewald (2003). ${ }^{22}$

0 No Research or Library Use Required: No evidence on syllabus of research or library use required.

1 Reserve Readings Only: Library use required for reserve reading.

2 Library Use for Outside Readings (Not Reserve): Library use required or expected to complete optional readings from a list supplied by the professor.

3 Some Research or Library Use for Shorter Assignments: Some research or library use required for shorter class presentations or shorter writing assignments, e.g., ancillary reading assignments that require self-directed, exploratory behavior. (This category implies the use of general library or Internet material, not reserve materials).

4 Significant Research Projects: Research or library use required for term papers and other research projects of some significance. "Significance" is defined as cumulative pages totaling at least ten and/or value to final grade of at least 20 percent.

Two reviewers were assigned to examine each syllabus. After all the syllabi were reviewed, those syllabi with a different rating assigned between the first and second reviewer 
Table 1. Distribution of Syllabi Across Disciplines $(N=144)$

Arts \& Letters-Humanities

$33 \%$

Arts \& Letters-Social Sciences

$18 \%$

Arts \& Letters-Arts

$12 \%$

Arts \& Letters-General

$8 \%$

Business

$12 \%$

Engineering

Science

Architecture

General

were flagged. ${ }^{23} \mathrm{~A}$ total of 49 syllabi were flagged and then reviewed by all six team members to arrive at a consensus rating. For most syllabi, team consensus was easily achieved. When it was not, the team attempted to contact the instructor for clarification. In cases where a consensus could not be reached, the lower rating was used.

In addition to assigning a level of library usage for each course, we noted whether or not the course included a formal library instruction component, as indicated on the syllabus, and whether the instructor was using the online CMS.

\section{ANALYSIS/RESULTS}

A summary analysis of the 144 randomly selected course syllabi showed that 62 syllabi (43 percent) required no library use. In contrast, 55 syllabi (38 percent) required use of library materials other than for reserves or assigned readings. Figure 1 shows a frequency distribution for the syllabi sampled. ${ }^{24}$

Happily, the data did not support our first hypothesis that a majority of the classes would not require library use. While 43 percent of the classes did not require use of the library at all, 57 percent of the courses did require library use, at least to some degree. Also, even though our rating systems varied to some degree, our figures compare favorably to the results of similar syllabus studies described earlier in this article. Figure 2 shows the comparison of syllabi requiring no library use at Notre Dame with the syllabi at other universities. Nonetheless, even though the majority of syllabi indicated some library use, if only minimal, there are clearly many classes that do not require any degree of library use, providing the library with many opportunities to reach out to faculty to embed the library and its resources into their curriculum.

The data did support our second hypothesis which was that the level of the class (freshman-100, sophomore-200, etc.) would affect the amount and degree of library research required, with the more advanced classes requiring more library research. As shown in figure 3, the percentage of course syllabi requiring library use increases as the class level increases. Chi-squared analysis yields a p-value of 0.03 , indicating that there is a statistically significant relationship between required library use and class level for our sample..$^{25}$

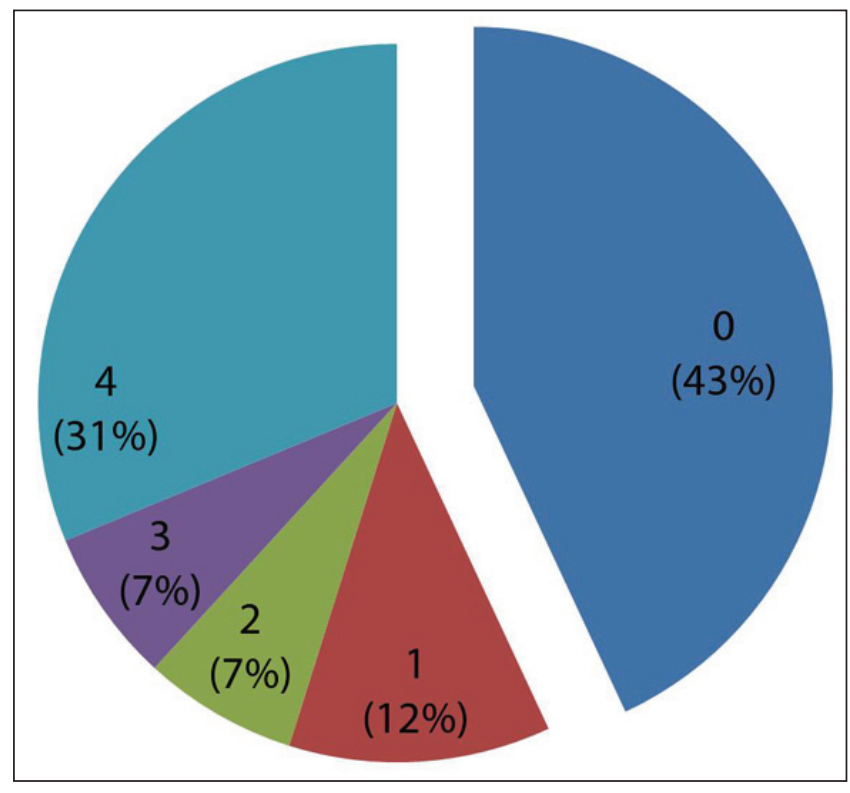

Figure 1. Number of Syllabi By 0 to 4 Rating $(N=144)$

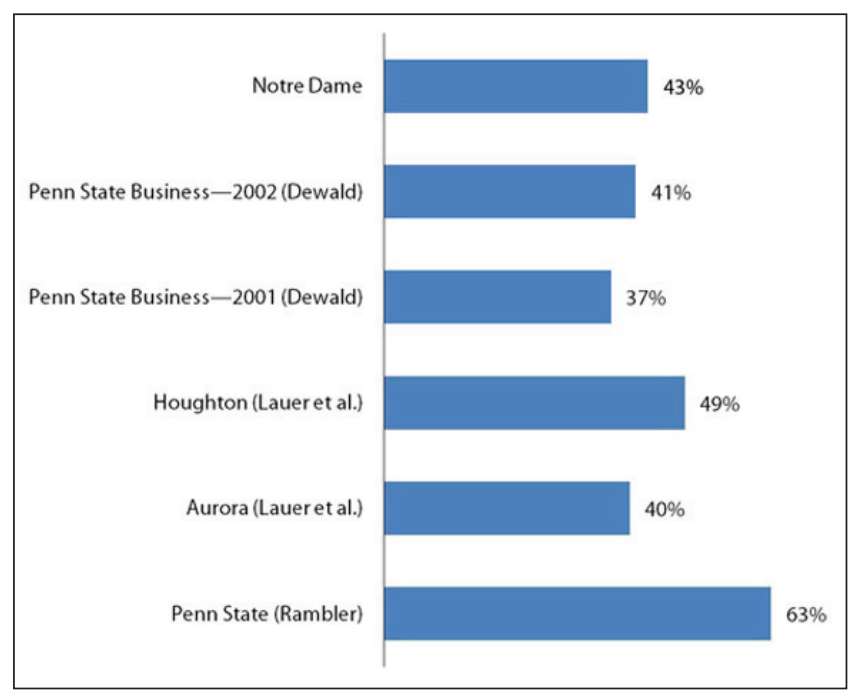

Figure 2. Comparison of Syllabi Requiring No Library Use

The data supported our third hypothesis that the subject discipline of the course would affect the amount of library research required, with art/architecture and the social sciences requiring the most library use and business and the sciences and technologies requiring the least amount of library use. This hypothesis was tested in two ways. The first method compared each of five broad disciplines to each other; the second method compared science-technology syllabi to the rest of the syllabi (two groups). Figure 4 shows the percentage of syllabi requiring some library use/research across broad subject area. Chi-squared analysis yielded a p-value of 0.03 , supporting our hypothesis that the amount of library use required does differ significantly across disciplines.

The data also supported our hypothesis that science and 


\section{FEATURE}

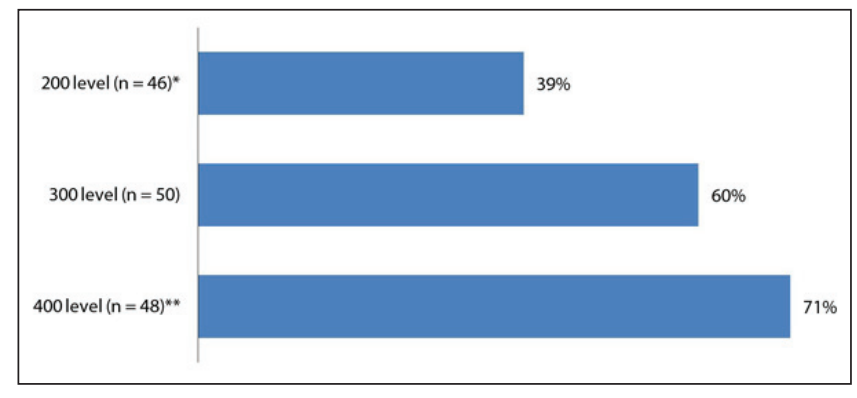

Figure 3. Percentage of Syllabi Requiring Some Library Use (Rating of 1, 2, 3 or 4) By Class Level

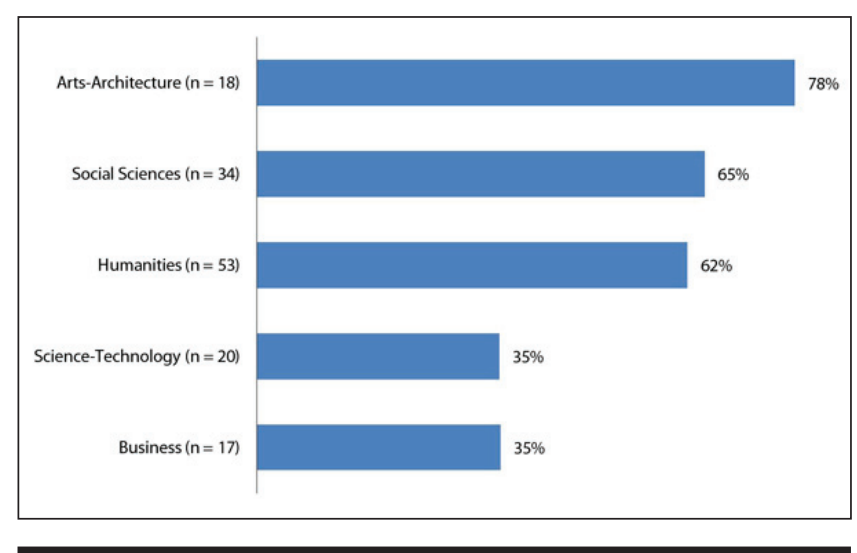

Figure 4. Percentage of Syllabi Requiring Some Library Use By Subject $(N=142)$

Note: Excludes 2 ROTC classes (rating of 0 ) because they did not fit easily with another subject.

technology classes would require a lower level of library use. Figure 5 compares the percentage of science and technology classes requiring some library use with all other disciplines. Chi-squared analysis yielded a p-value of 0.05 , indicating that science and technology courses require a significantly lower level of library use. ${ }^{26}$

The data supported our fourth hypothesis that for those courses requiring library use, the use of the University's CMS in general would be low. Of the 144 syllabi examined, 29 (20 percent) referred to the CMS. However, only 12 (8 percent) required some degree of library use (rating of 3 or 4 ). See figure 6 for the number of syllabi requiring the use of the CMS broken by rating (0-4).

There were no similar studies available with which we could compare Notre Dame's results, so statistical significance was not determined. As expected, though, for those syllabi requiring library research, the use of the University's CMS is in fact low and supports what we already believed based on purely anecdotal evidence.

Data also supported our hypothesis that formal library instruction services would be underutilized for those classes requiring some or much library use. Of those 55 syllabi indicating that significant library research is required (those

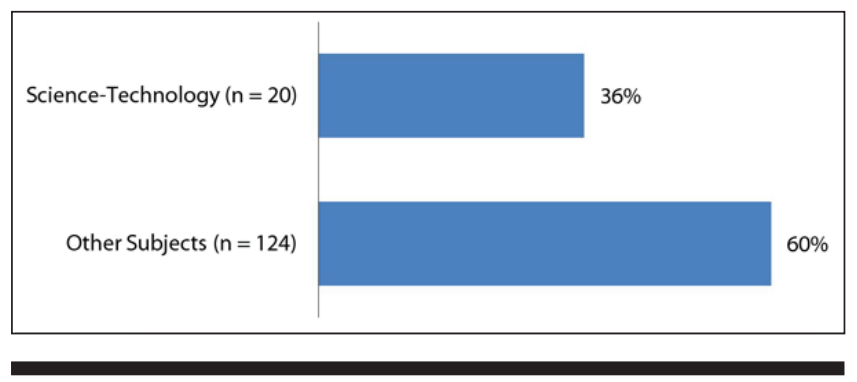

Figure 5. Percentage of Syllabi Requiring Some Library Research, Science-Technology vs. Other Subjects $(N=144)$

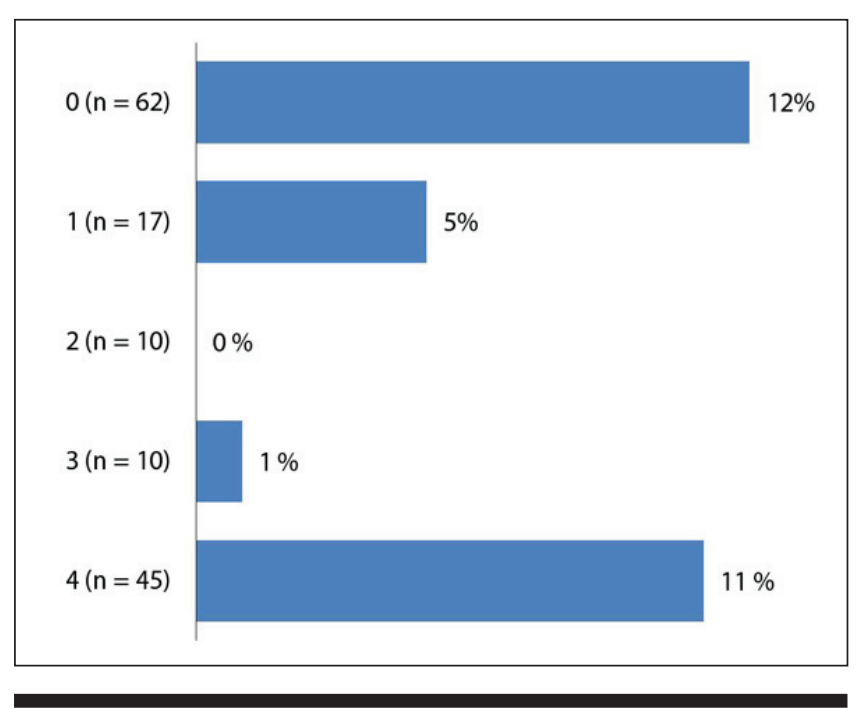

Figure 6. Number of Syllabi Requiring the CMS by Rating (0 to 4)

rated as a 3 or 4), only 6 (11 percent) showed any evidence of formal library instruction. When we compared the list of syllabi sampled to our records of formal library instruction activities, we discovered that two additional classes had received instruction, even though it had not been indicated on the syllabi.

The other syllabus studies did not analyze the relationship between library use and formal instruction in the same manner, so we were not able to determine statistical significance. Nonetheless, the numbers clearly show that our instructional services are underutilized, for whatever reasons, and that further exploration into why faculty are not taking advantage of these services is certainly warranted.

Two of the more interesting relationships that were uncovered involved the maximum enrollment for a class and days of the week that the class met. The maximum enrollment numbers were combined into four groups (18 or less, 19 to 24, 25 to 40, 41 and over). Chi-squared analysis yielded a $\mathrm{p}$-value of 0.14 . This is greater than the benchmark p-value of 0.05 , but still indicates that there is some relationship between enrollment and library usage. When the maximum enrollment for a class was 41 or more, the syllabi were more likely to require no library research. 
We also examined the days of the week that the class met by dividing the classes into two groups: $\mathrm{M}-\mathrm{W}-\mathrm{F}$ (or any combination thereof), and T-Th (or any combination). Chi-squared analysis yielded a p-value of 0.11 (not statistically significant, but still some relationship) and revealed that $\mathrm{T}-\mathrm{Th}$ classes were more likely to require library research than $\mathrm{M}-\mathrm{W}-\mathrm{F}$ classes.

\section{DISCUSSION}

The goal of this project was to examine course syllabi to locate avenues for future collaboration with teaching faculty and to better target our outreach for library instruction either through formal classroom instruction or through embedding services into courses. Though our study confirmed that library resources and services are underutilized, we were able to uncover some useful information about patterns of library use and potential areas for future library outreach.

It is encouraging that there was a higher percentage of classes (57 percent) requiring some type of library component than classes without any library component (43 percent), and this would seem to indicate that many faculty are aware of and value the library resources available to them and to their classes. We were, however, discouraged to find that, of the 57 percent that did include a library research component in their syllabi, only eight of these classes included any formal library instruction. While we had predicted that formal library instruction would be underutilized, it was disappointing nonetheless to see the large number of classes that required a research component but did not mention librarians or library instructional services on their syllabi.

It would be beneficial to study the factors that influenced this exclusion. For example, are faculty assuming that information literacy skills have already been acquired at the freshman level? Our study of 200- to 400-level classes revealed that library use increases with the level of the course. If our tiered approach to instruction is to be successful, we should expect higher levels of library instruction in upper-level classes compared to lower-level classes. Introductory skills should be taught in 100- or 200-level classes, and advanced instruction should be integrated into upper-level classes.

It is clear that faculty expect students in their upper-level classes to use the library in the course of their studies, but it is also clear that they expect them to use library resources with little or no advanced instruction or guidance from librarians. Faculty may not be aware that many students leave the First Year of Studies with no exposure to library resources or information literacy skills because they test out of First Year Composition. Therefore it is our responsibility to raise faculty awareness of the research skills that their students may be lacking.

Our data showed that the subject of the classes did have an impact on the extent to which library resources are incorporated into the syllabi. As we predicted, science and technology classes required lower levels of library use. If laboratory classes had been retained in the study, it is possible that library use would have been higher. We were surprised to learn that the humanities did not have the highest percentage of classes requiring library use when compared with social sciences and arts/architecture. Though not formally stated as a hypothesis, we were expecting that library use would be highest in the humanities. During the course of our examination of the syllabi, we did notice that many classes in the humanities required significant writing assignments, but many of these assignments were based on assigned readings instead of independent library research. Writing assignments in the social sciences, however, tended to require the use of course reserves, recommended readings, or fully independent student research. The study revealed that faculty in the social sciences and humanities tend to require more library use, and focusing our outreach efforts in these areas would be of value. In the humanities, we could suggest to faculty the possibility of adding small independent research components to their existing writing assignments that would introduce upper-level humanities students to more advanced information literacy skills.

It was surprising to find that library use was low in business courses. Librarians in the Business Information Center (BIC - an all-electronic business branch library) occasionally collect syllabi to look for research trends and instructional opportunities. While assisting students with questions about their assignments, the BIC staff has learned that some professors do not use the electronic course reserves offered by the Libraries, using outside providers to generate printed course packs for their students instead. Raising awareness of the cost-saving potential of the library reserve system could provide a first step toward increased library involvement in those business classes that currently include no library component. The low rate of library use in business courses merits further study. The need for library resources and services in this discipline is major and becomes more important as more specialized library databases and other resources become available, so any increase in library involvement in classes would be desirable.

Our study showed that approximately 20 percent of the classes used the CMS. While the CMS is still not heavily used in all disciplines, it could be an avenue for outreach. Course pages within the CMS provide excellent opportunities for collaboration between librarians and the teaching faculty. Links to the Libraries and the electronic reserve system are already included in the CMS template. It could be modified to include links to course pages and subject specialists. Making greater efforts to determine which members of the teaching faculty are actively using the CMS could provide further opportunities for embedding library resources and services.

Additional analysis of the data uncovered some very interesting correlations. We discovered that there is some relationship between the days of the week on which classes are taught and the amount of library research required. T-Th classes are usually one hour and fifteen minutes in duration and showed a higher percentage of library use than the M$\mathrm{W}-\mathrm{F}$ classes which are fifty minutes long. It is difficult to determine why this would be the case, but one possible reason 


\section{FEATURE}

could be that the faculty who meet with their students less frequently are more willing to have their students work on longer assignments outside of the classroom. More analysis will be necessary to determine why M-W-F classes are less likely to incorporate library resources into their syllabi.

Our data indicated that smaller classes with less than 41 students had more library involvement, possibly because faculty who teach large classes may find it too time-consuming to evaluate extensive research projects. Outreach to faculty with larger classes could focus on embedding library resources into the syllabi or working with the faculty to design different types of assignments, such as annotated bibliographies, as alternatives to research papers.

\section{CONCLUSION}

In conclusion, by collecting syllabi we were able to determine that 57 percent of the classes surveyed did use the library to some degree, and 38 percent required that students use library resources to a fairly high degree. It was gratifying to find that more than half of the classes used the library to some extent, but it was somewhat disappointing to find that only a small percentage of these classes scheduled library instruction sessions or mentioned librarians in their syllabi. We were able to determine that library usage was highest in the social sciences and arts/architecture and lowest in the sciences, technology, and business. We also determined that smaller classes and classes taught on Tuesdays and Thursdays were more likely to require library use than larger classes and M-W-F classes.

This study sheds some light on potential directions for the library instruction program at the University of Notre Dame. While traditional library classroom instruction is a valuable way to introduce information literacy skills, there are other ways to integrate library resources into courses including the creation of course pages, mini-instruction sessions, research consultations, collaboration in creating library assignments, etc. Our CMS also may open more opportunities for embedding library services.

This study also revealed the value of examining course syllabi as a method for uncovering opportunities for instruction and outreach. Our examination has revealed many ways that we might collaborate with faculty who are not currently using our services, including assisting faculty with the design of assignments. Librarians should regularly request syllabi from teaching faculty to identify avenues for incorporating both traditional and nontraditional information literacy components into classes. Taking advantage of these opportunities effectively embeds librarians into the curriculum and builds partnerships with faculty to create information literate students.

\section{References and Notes}

1. American Library Association, Presidential Committee on Information Literacy, final report (Chicago: ALA, 1989).

2. See Esther S. Grassian and Joan R. Kaplowitz, Information Literacy Instruction: Theory and Practice (New York: Neal-Schuman, 2001).
3. Wendy Holliday and Britt Fagerheim, "Integrating Information Literacy with a Sequenced English Composition Curriculum," portal: Libraries \& the Academy 6, no. 2 (2006): 169-84.

4. Trudi E. Jacobsen and Beth L. Mark, "Separating Wheat from Chaff: Helping First-Year Students Become Information Savvy," Journal of General Education 50, no. 4 (2001): 323.

5. K. Bergen and B. MacAdam, "One-to-One: Term Paper Assistance Programs," RQ 24, no. 3 (Spring 1985): 333-40.

6. Ann Grafstein, "A Discipline-Based Approach to Information Literacy," Journal of Academic Librarianship 28, no. 4 (2002): 197.

7. Christopher Cox, "Becoming Part of the Course," College $\&$ Research Libraries News 63, no. 1 (2002): 11.

8. Lisa M. Williams, Sue Ann Cody, and Jerry Parnell, "Prospecting for New Collaborations: Mining Syllabi for Library Service Opportunities," Journal of Academic Librarianship 30, no. 4 (2004): 270-75.

9. Jeremy W. Sayles, "Course Information Analysis: Foundation for Creative Library Support," Journal of Academic Librarianship 10, no. 6 (1985): 343

10. Linda K. Rambler, "Syllabus Study: Key to a Responsive Academic Library," Journal of Academic Librarianship 8, no. 3 (1982): 155.

11. Ibid., 159.

12. Jonathan D. Lauer, Lawrie H. Merz, Susan L. Craig, "What Syllabi Reveal about Library Use: A Comparative Look at Two Private Academic Institutions," Research Strategies 7, no. 4 (Fall 1989): $167-74$.

13. Ibid., 173.

14. R. Bean and L. M. Klekowski, "Course Syllabi. Extracting their Hidden Potential," in The Sixth Off-campus Library Services Conference Proceedings (Mount Pleasant, Mich.: Central Mich. Univ. Pr., 1993): 1-9.

15. Ibid., 4 .

16. Nancy H. Dewald, "Anticipating Library Use by Business Students: The Uses of a Syllabus Study," Research Strategies 19, no. 1 (2003): 33-45

17. Lauer et al. "What Syllabi Reveal about Library Use," 167-74

18. Williams, et al., "Prospecting for New Collaborations," 270-75.

19. Ibid., 275 .

20. Ibid., 273.

21. Amy VanScoy and Megan J. Oakleaf, "Evidence vs. Anecdote: Using Syllabi to Plan Curriculum-Integrated Information Literacy Instruction," College \& Research Libraries 69, no. 6 (2008): 566-75.

22. Lauer, et al. "What Syllabi Reveal about Library Use," 167-74; Dewald, "Anticipating Library Use by Business Students," 33-45.

23. One team reviewed 46 syllabi and had an overall kappa coefficient of inter-observer agreement of 0.53. A kappa coefficient between 0.40 and 0.60 indicates moderate agreement, according to Douglas G. Altman, Practical Statistics for Medical Research (London: Chapman and Hall, 1991). (Though Altman is dated, it has a clear and concise explanation of kappa values). The second team reviewed 53 syllabi and had a kappa coefficient of 0.41 . The third team reviewed 46 syllabi and had a kappa coefficient of 0.77 .

24. Note that the data are not normally distributed, and that the scale is ordinal ("no use required" to "much use") and discrete. The average (mean) rating for all syllabi was 1.7 , which means that the average falls somewhere between 1 and 2, but closer to 2.1.7 on its own has no referent. Because the distribution is not parametric, the confidence interval for the mean and the standard distribution are not reported here.

25. It should be noted that to minimize the violations of the chisquared analysis constraints, 100-level classes were combined with 200-level, and 500-level with 400.

26. Though the analysis as shown violates the constraints of chisquared analysis, when adjusted, the relationship is still significant at a p-value less than or equal to 0.05 . 


\section{APPENDIX. E-MAIL TO COURSE INSTRUCTORS}

Dear Professor X,

A study is being done to determine the extent to which library resources and services are incorporated into coursework at Notre Dame. To do this, several librarians are examining syllabi from randomly selected courses being offered this semester. One of your courses has been randomly selected for our study:

\section{CSE 4054701 Computing at the Nanoscale}

Please take a moment to reply to this message by May 1st, 2009, and attach an electronic copy of your syllabus for this class, or mail a print version of the syllabus to me (name of the e-mail's sender) at [author's address].

You will not be identified by name in our study. We are interested in seeing your syllabus even if there is no library component in your class. If we have questions, we may need to get back in touch with you.

Please let us know if you are not interested in participating.

Thank you, and please contact me if you have any questions or comments about this request.

Sincerely,

Team Member 


\section{Does Telling Them to Ask for Help Work? Investigating Library Help-Seeking Behaviors in College Undergraduates}

\section{Catherine Pellegrino}

Catherine Pellegrino is Reference Librarian/Instruction Coordinator, Saint Mary's College, Notre Dame, Indiana. Submitted for review June 17, 2011; accepted for publication August 19, 2011.

Reference \& User Services Quarterly vol. 51, no. 3, pp. 272-77

(c) 2012 American Library Association. All rights reserved.

Permission granted to reproduce for nonprofit, educational use.
The article seeks to answer the research question: are students who attend a library instruction session in which they are encouraged to ask for help at the library more likely to do so than students who do not attend such a session, or students who attend a session but are not encouraged to ask for help. The researcher designed a survey, the results of which did not show a statistically significant relationship between students who were encouraged by a librarian to ask for help, and students who did. The survey did, however, show a statistically significant, strong positive relationship between students who were encouraged or required by faculty to ask for assistance and students who did so. Implications of these results for library-based strategies to increase the proportion of students who obtain research help are discussed.

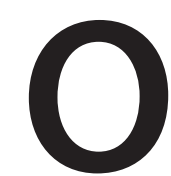
ne of the defining characteristics of the academic library is the desire on the part of both the organization and the people who staff it to help students find, access, evaluate, and use information. We have known for a remarkably long time that students do not make as much use as they might of the help that is available to them at their college or university's library, and considerable research has been done on the reasons why, mostly collocated under the heading "library anxiety." Yet very little is known about what strategies are effective at overcoming library anxiety. The research reported in this article attempts to evaluate the effectiveness of a very simple strategy: librarians, in the course of providing information literacy instruction, encouraging students to ask for help at the library.

Encouraging, even exhorting students to come to the library when they need help is such an obvious tactic and is practiced—with varying degrees of earnestness-on a daily basis in library instruction classrooms around the country. But does it work? Is it sufficient, or are there additional strategies and tactics that instruction librarians could and should be employing to ensure that every student who needs a librarian's help does, in fact, get that help? ${ }^{2}$

As a small step toward answering these questions, the researcher designed a survey-based study to address a considerably more specific research question: Are students who have attended a library session where they were explicitly encouraged to ask a librarian for help more likely to ask a librarian for help than students who have not attended a library session or who have attended a library session but were not explicitly encouraged to ask a librarian for help? 